\title{
Identifying applicants suitable to a career in nursing: a value-based approach to undergraduate selection
}

\section{Traynor, M}

http://hdl.handle.net/10026.1/8567

\author{
10.1111/jan.13227 \\ Journal of Advanced Nursing \\ Wiley
}

All content in PEARL is protected by copyright law. Author manuscripts are made available in accordance with publisher policies. Please cite only the published version using the details provided on the item record or document. In the absence of an open licence (e.g. Creative Commons), permissions for further reuse of content should be sought from the publisher or author. 
Received Date : 03-Jun-2016

Revised Date : 10-Oct-2016

Accepted Date : 08-Nov-2016

Article type : Original Research: Empirical research - quantitative

\section{Full Title:}

Identifying applicants suitable to a career in nursing: a value-based approach to undergraduate selection

\section{Running Head: \\ MMls in Nursing.}

\section{Author Details:}

Marian TRAYNOR, RGN, MEd, EdD. Senior Lecturer. Director of Education.

Despina GALANOULI, PhD, MSc. Research Fellow (Education).

Martin ROBERTS, MSc. Lecturer in Assessment Psychometrics

Lawrence LEONARD, RGN, MSC, Pg Dip Pub Health. Lecturer (Education).

Thomas GALE, BMedSci, FRCA, Med. Senior Lecturer. Associate Professor and Consultant Anaesthetist

\section{Corresponding Author:}

Marian TRAYNOR, RGN, MEd, EdD. Director of Education.

Email: m.traynor@qub.ac.uk

This article has been accepted for publication and undergone full peer review but has not been through the copyediting, typesetting, pagination and proofreading process, which may lead to differences between this version and the Version of Record. Please cite this article as doi: $10.1111 /$ jan.13227

This article is protected by copyright. All rights reserved. 


\section{Funding}

This research did not receive any specific grant from funding agencies in the public, commercial, or not-for-profit sectors.

\section{Declaration of interest}

The authors report no conflicts of interest. The authors alone are responsible for the content and writing of the article.

\section{ABSTRACT}

Aims

To complement existing evidence on the suitability of Multiple Mini Interviews as potential tool for the selection of nursing candidates on to a BSc (Hons) nursing programme.

\section{Background}

This study aimed to trial the Multiple Mini Interview approach to recruitment with a group of first year nursing students (already selected using traditional interviews).

\section{Design}

Cross-sectional validation study. This paper reports on the evaluation of the participants' detailed scores from the Multiple Mini Interview stations; their original interview scores and their end of year results.

\section{Methods}

This study took place in March 2015. Scores from the seven Multiple Mini Interview stations were analysed to show the internal structure, reliability and generalisability of the stations. Original selection scores from interviews and in-course assessment were correlated with the MMI scores and variation by students' age, gender and disability status was explored. 


\section{Results}

Reliability of the Multiple Mini Interview score was moderate $(\mathrm{G}=0.52)$. The Multiple Mini Interview score provided better differentiation between more able students than did the original interview score but neither score was correlated with the module results. Multiple Mini Interview scores were positively associated with students' age but not their gender or disability status.

\section{Conclusion}

The Multiple Mini Interview reported in this study offers a selection process that is based on the values and personal attributes regarded as desirable for a career in nursing and does not necessarily predict academic success. Its moderate reliability indicates the need for further improvement but it is capable of discriminating between candidates and shows little evidence of bias.

\section{KEYWORDS}

nursing recruitment, multiple mini interviews, interview scores, personal statement, values based recruitment, selection

\section{SUMMARY STATEMENT}

\section{Why is this research needed?}

- Recent reports on standards of care provided by health care professionals have led to questions around recruitment into nursing of the right people with the right values.

- It is good practice for Higher Education Institutions to review selection methods against the best available evidence and demonstrate the application of robust quality assurance procedures to the selection methods used for entry to university. 


\section{What are the key findings?}

- The Multiple Mini Interview as reported in this study has the ability to differentiate between more able students and contributes to the well-established evidence supporting Multiple Mini Interviews as a selection method; however the Multiple Mini Interview does not necessarily predict academic success.

- Scores for the personal statement, generally regarded as an unreliable measure on which to select applicants, were significantly positively correlated with academic results.

\section{How should the findings be used to influence policy/practice/research/education?}

- Findings will contribute to the debate on selection to nursing and contribute to the literature around Multiple Mini Interviews.

- Findings can be used to influence the future selection to nursing as well as to influence policy on recruitment to fill registered nursing vacancies.

\section{INTRODUCTION}

The challenge for any academic institution in educating future nurses and midwives is to select candidates who possess values and attributes best suited to professional practice Fagermoen 1997, Weis \& Schank 2000, Perkins et al. 2013, Pitt et al. 2014, NHS 2014). The importance of selecting appropriate candidates who possess these values was highlighted in the Francis report (2013) which stated that poor standards of care at Mid- Staffordshire NHS were due to staff not having the right values or appropriate levels of professionalism. Values Based Recruitment (VBR) seeks to identify the values, beliefs and attitudes which are fundamental attributes of a professional nurse. It has recently become an important programme of work in the National Health Service, with the government directing Health 
Education England (HEE) to oversee the delivery of a national VBR framework to deliver high quality, effective, compassionate care: developing the right people with the right skills and the right values (HEE, 2014).

In the United Kingdom (UK), the Nursing and Midwifery Council (NMC) requires students to achieve a range of competencies to support learning and assessment in practice to be eligible for registration (NMC 2008). In their most recent guidance on pre-registration education the NMC stated: Professional values must underpin education as well as practice (NMC 2010, p.5), thus placing an increasing emphasis on the non-cognitive skills of nursing and midwifery students. Taylor and colleagues, in their review of selection processes for nurses in Scotland, have concluded that although selection is a process that all institutions are investing in and striving to improve, more evidence is needed to ensure that admissions decisions are based on best practice (Taylor et aI. 2014).

Consistent with these developments, research nationally and internationally has explored whether selection processes for nursing such as the personal interview (Morris 1999) are 'fit for purpose' and have examined alternative recruitment models. One selection model that has attracted undergraduate, nursing educational, providers' attention is the multiple mini interview (MMI) devised by Eva and his colleagues at McMaster University in Canada. This model was originally designed to recruit the highest quality of medical candidates from the cognitive and non-cognitive skills perspective (Eva et al. 2004). The main aim of this study was to evaluate the feasibility of using the MMI, with assessment of values relevant to nursing, for entry to an undergraduate nursing programme. 


\section{Background}

Following the publication of the Francis report (2013), we reviewed our selection process at our institution to establish a process that would guarantee that recruitment decisions were made not only on academic ability but also values and attitudes necessary for a career in nursing. At the time, the School's selection procedure, consistent with most UK nursing education providers, was focused on personal interviews after a preliminary screening through personal statements and assessment of academic ability. The Department of Health, Social Services and Public Safety (DHSSPS) recently identified a need to review the selection processes and commissioned a formal review in Northern Ireland (Gateway to Nursing, NIPEC 2014)

Cleland et al. (2012) undertook a comprehensive review of selection methods used by medical schools, with a particular emphasis on values and attributes of applicants. This report concluded that the evidence for MMIs, aptitude testing, Situational Judgement Tests and selection centres is 'better' overall than that for traditional interviews, references and autobiographic reports.

\section{MMI method of student selection}

The MMI developed by Eva et al. (2004) is modelled on the Objective Structured Clinical Examination and consists of several stations each with a different examiner. This allows multiple samples of insight into a candidate's abilities and dilutes the effects of chance and interviewer/situational bias. Stations are designed to test specific competencies and attributes such as communication, empathy, critical thinking and ethics. Assessment blueprinting can be aligned to personal qualities which an individual institution chooses to reflect their own values and curriculum (O’Brien et al. 2011). A 2013 systematic review found that MMIs 
used in selection to medicine and other healthcare professions have shown moderate to high reliability (Cronbach's alpha $=0.69-0.98, \mathrm{G}=0.55-0.72$ ), did not correlate to traditional admission tool scores or pre-entry academic qualifications but were predictive of subsequent OSCE and medical council examination performance (Pau et al, 2013). They have also been shown to be cost effective; have increased validity (Eva et al. 2004, Patterson et al. 2005, Randall et al. 2006) and produce positive candidate feedback and reliability (MSC, 2013).

While MMIs have been used in medical student recruitment since Eva's study (Poole et al. 2009; O'Brien et al. 2011), this method was adopted only recently for selection of nursing and midwifery candidates. In 2011, the School of Nursing at Kingston University and St George's, University of London, adopted the MMI for their nursing candidates following the introduction of similar procedures for medical students (Perkins et al. 2013) Candidates to the nursing programme were asked to complete a questionnaire to evaluate their experience of the MMI in comparison to the experience of the traditional panel interview selection process. The majority (65\%) of candidates considered it to be a better experience overall. The MMI was fairer and gave additional opportunities to candidates plus assessor feedback found that $71 \%$ favoured the MMI as a better method of selection.

At the University of Surrey, Callwood and her colleagues, presented the case for using MMIs in the recruitment of nursing and midwifery students (Callwood et al. 2012) before following up with piloting this method by carrying out 'mock' MMIs with existing midwifery students. This pilot addressed a requirement of their University's Admissions Board for the adoption of this method as a new recruitment procedure (Callwood et al. 2014). Despite certain limitations of this pilot, such as the use of a self-selected sample of students who were already admitted to the course, the MMI recruitment process was described as 'uneventful', 
attracted positive feedback from both assessors and students and was officially adopted by that institution for the recruitment of midwifery students.

Following successful pilots and evaluations of face validity the MMI has been adopted in at least two Higher Education Institutions (HEIs) in the UK for undergraduate nursing programmes (Callwood et al. 2012), (Callwood et al. 2014) (Perkins et al. 2013). HEIs are ideally placed to work alongside clinical colleagues to develop stations that will suitably test candidates' attributes for nursing. Traditional interviews generally require applicants to report characteristics they possess that would make them a good nurse (Draper and Kenward, 2013). However, it is extremely unusual if a candidate does not respond by listing 'caring', 'compassion' and 'empathy' as these characteristics. The MMI can elucidate these characteristics through role playing life-like scenarios.

Our study sought to develop an MMI process based on the assessment of generic values appropriate for nursing and pilot this method across one cohort of nursing students at our institution. . The participating students already had a place on the course having previously passed a traditional style interview and achieved the academic standards for admission. Consequently the pilot MMI did not require the establishment of a cut score as the students were already selected.

\section{Project Group}

A project group was established to oversee the pilot with membership of the Head of the University Admissions as well as experts in the field of MMIs and selection, service users, students and clinicians. The project group had the following specific objectives:

1. To agree a blueprint for the MMI research study

2. To agree the number and nature of stations 
3. To agree domains/values per station

4. To obtain approval from School Research Ethics Committee to conduct 'mock' interviews on selected cohort of students

5. To organise staff training for the MMI.

\section{THE STUDY}

Aims

The aim of the study was to collect and evaluate validity evidence for the MMI as a potential selection method for the recruitment of Nursing and Midwifery students that have attributes and behaviours suited to nursing.

This paper will focus on the evaluation of the MMI stations used in this pilot; their internal structure, validity and reliability and how these MMI scores compared with the students' original personal interviews scores for their admission on the course. The predictive validity of the MMI and the original selection (from both personal statements and interviews) scores in terms of how they could predict in-course performance will be compared.

\section{Design}

The research design was a cross-sectional validation study. The volunteers, both students and lecturing staff, were provided with background information to the study and required to offer their informed consent. The main research activity required participants to act as candidates and assessors in several standardised MMI stations under formal interview conditions. The station scenarios were reviewed by both academic and clinical staff with previous experience of the MMI process and cross referenced against the NMC competencies and attributes that 
are valued to support a career in nursing (NMC, 2010) and also the attributes valued to realise future potential for a career in nursing published by NIPEC (2014).

\section{Participants}

A convenience sample was used by inviting all first year undergraduate nursing students $(\mathrm{N}=318)$ to participate in the research study; all other year students and midwifery students were excluded. The first year was selected on the basis that the students had a recent experience of the current selection process having been interviewed the previous year for their nursing course and therefore they would be better placed to compare the two different selection processes. It was decided that the sample would be limited to the first 192 volunteers due to space and time restrictions. This was judged an acceptable sample size in comparison with other published studies evaluating the MMI (e.g. 117 participants in Eva and colleagues' 2004 study and 62 participants in Callwood and colleagues' 2014 study). This sample size would allow estimation of correlation coefficients within a $95 \%$ confidence interval of \pm 0.14 and estimation of percentage agreement with Likert-scale questionnaire items within a $95 \%$ confidence interval of $\pm 7 \%$. Assuming a correlation of 0.70 between MMI scores and interview scores at entry (i.e. 50\% shared variance) a power analysis using G*Power (Faul et al. 2009) showed that the analysis would have $80 \%$ power to detect, at the $5 \%$ significance level, a difference of 0.15 in the correlations of these scores with in-course assessments.

Recruitment took place over a two month period. Interested students received a participant information statement and consent form. To boost numbers a further email was sent and also a personal invitation by the researchers took place during one of the cohort's lectures. 
Thirty two assessors were recruited to take part in the MMI, through email invitations to all clinical and academic staff previously involved in the interview process and information events.

Incentives

In an effort to maximise student participation the students' attention was drawn to the following:

- First year students are required to take objective structured clinical examinations (OSCEs) which have been known to cause stress (Cazzell \& Rodriguez 2011, Traynor \& Galanouli 2015); the MMI process is very similar in terms of format to the OSCEs and therefore participation in this study would offer them useful practice in preparation for this clinical examination.

- A certificate for participation in this research was offered to students who could use it towards their Degree Plus Award (an award offered by this University to accredit learning and skills developed through extracurricular activities and awarded to students on graduation).

Data collection

The following sources were used to evaluate the MMI process:

- Participants' detailed scores from the seven MMI stations;

- participants' original interview scores when they applied to the HEI;

- participants' end-of-first year academic results; 


\section{MMI stations}

The MMI project group agreed to develop seven stations, each five minutes in duration, including one focusing on the students' personal statement as an ice-breaker plus one resting station. The total time for this activity was 40 minutes. Stations were written by members of the MMI project group while one member of the group from Medicine with extensive experience in selection methods acted as critical friend. The whole MMI project group then reviewed for clarity of meaning and usability and the scenarios were refined. Each scenario was based on testing attributes associated with specific sets of values as outlined by the Gateway to Nursing report (NIPEC, 2014). The values tested were trust; integrity; accountability; personal development; person centeredness and team working. These were mapped to the seven stations (Figure 1).

\section{Assessors}

Thirty two assessors participated in the MMI trial, of whom 23 were staff from the School of Nursing and Midwifery and nine were clinical staff from one university affiliated teaching hospital. They all attended briefing and training sessions and were required to give informed consent before participating in the study. We wished to explore inter-rater agreement by deploying two assessors in each station throughout the MMI but this was not possible due to limited availability. We therefore deployed a second assessor in stations 1, 2, 3 and 6 for some of the students as these stations were considered more difficult to assess due to the use of role players in the first three and the nature of the task in the last.

\section{Role players}

The first three stations involved a role player/simulated patient participating in a scenario played out between them and the nursing candidate. Role players attended a briefing/training session where they had an opportunity to rehearse their stations with students (not involved in 
the study) helping pilot them. Nine role players were recruited plus one as a reserve. They provided their own separate score for each candidate which was not taken into account for the marking of the stations but was used during the data analysis stage to explore whether role players' scores correlated with those of the assessors. A role player score sheet was made available to the role players as a guide to the scoring process.

\section{Marking of MMI stations}

Scoring sheets developed by the MMI working group were used; these were subsequently scanned by an optical mark reader. The assessors were required to mark each value separately (for example, for station 1 the values to be assessed were trust, accountability and person centeredness). These were scored from 'weak' to 'excellent' with a range of six. Also, to provide a separate global score, descriptors were provided through a global score sheet as a guide for the assessors to indicate their overall impression of those values displayed in that station. Global scores ranged, again, from 1-6 with descriptors ranging from 'weak' to 'excellent'. The role player score was communicated to the assessor by the role player at the conclusion of each candidate session and was entered on the score sheet.

\section{Briefing of participants}

Participants were welcomed and thanked by a member of the project team for participating and were given general information on the format of the MMIs including housekeeping rules. The background rationale for the MMI was explained and the process explained, i.e. the floor plan of circuits, the number of interview stations ( 7 stations, 5 minutes each), the general nature of each station and that some stations would include an interviewer with a role player. Participants were given the opportunity to ask questions for clarity on the process. A 
debriefing session was held, affording participants the opportunity to give feedback, to discuss any issues that had arisen and to hear general views regarding the MMI process.

\section{Ethical considerations}

A Research Ethics Application was submitted to the School of Nursing and Midwifery Research Ethics Committee in November 2014. All ethical issues were properly addressed including information statements and informed consent forms for both student and staff participants. Considering the proposed data analysis it was judged necessary to ask student permission to access their original interview results as well as end of year results; also their personal data including age, gender and disability status. The anonymization of the data and its safe-keeping were also addressed, as well as the sharing protocols between this University and the collaborating HEI.

Although there was no anticipated risk to the participants, they could be perceived as vulnerable in the sense that they were students and they might be anxious that refusal to participate in the research could have adverse effect on their studies, particularly when the Chief Investigator (CI) was the Director of Education of the School of Nursing and Midwifery. Therefore all communications with potential participants, both oral and written, prior to recruitment, made it clear that they were under no obligation to volunteer and that involvement in the research would have no effect on their studies, positive or negative and that they could withdraw at any stage of the process without any consequences. To reduce the possible power relationship effect between the CI and the students, the research fellow was the main contact for the project and communicated with the students. Furthermore, it was made clear that the focus of the study and the evaluation was the MMI tool and not individual participants' performance. 


\section{Data analysis}

Scores from the seven MMI stations were analysed using SPSS v19 to show the internal structure, reliability and generalisability of the stations. Original selection scores from interviews and in-course assessment were correlated with the MMI scores:

- Interrater agreement was measured by a two-way random effects intraclass correlation coefficient.

- The internal structure of the MMI was evaluated by calculating interstation and station-total correlation coefficients

- Reliability of the overall MMI score was measured by calculating Cronbach's alpha and generalisability coefficients.

- Factors affecting variance in scores for the MMI were measured using generalisability analysis from which D-studies were used to estimate the reliability of the MMI process for different combinations of stations in future MMIs.

- MMI scores were correlated with participants original selection scores (personal statement and interview scores) and with end of year results on their undergraduate course.

- Regression analyses using: (i) the MMI score; and (ii) the original interview score as the outcome variable were conducted to identify any variation in average scores between demographic subgroups of students.

\section{RESULTS}

\section{Participant profile}

Recruitment concluded with 128 students agreeing to participate in the pilot which was due to run in March 2015. On the actual pilot day, 110 students were present and were assessed by 32 assessors. The demographic profile of the students was as follows: 
- $101(92 \%)$ were female

- Ages ranged from 19 to 48 years (median 24 years).

- There were 10 students with specific learning difficulties, 3 with other disabilities, 97 with no disability

Station score distribution

The range of scores awarded in each station, along with their mean and standard deviation are shown in Error! Reference source not found.

\section{Overall MMI score distribution}

Maximum achievable score for the MMI was 168 points, minimum 28 points. Actual scores ranged from 80-144 and were approximately normally distributed with a mean (SD) of 114.2 (13.0) points (Figure 2).

\section{Internal structure and reliability}

Correlations of the station scores with each other and with the corrected overall MMI score (excluding the station itself) are shown in Table 2. These scores were generally positively correlated suggesting reasonable consistency between the stations. Scores for Station 4 however, were negatively correlated with some of the other stations (particularly with Station 2) and uncorrelated with the overall MMI score, indicating that this station is measuring a different aspect of candidate ability to the other six stations.

Cronbach's alpha for the overall MMI score was 0.49 , considerably less than the reliability threshold of 0.70 that is considered desirable for such a high stakes assessment. Removal of Station 4 caused the alpha to increase to 0.58 , underlining the inconsistency of this station with the other six. 


\section{Interrater agreement}

Agreement on the total station score was very good in stations 2 and 3 but weaker in stations

1 and 6 (Table 3). Coefficients for the value and global rating items show which ones lead to better or poorer agreement in each station.

\section{Generalisability}

Generalisability analysis of the station scores showed that of the variance in scores on individual stations; $13 \%$ was due to differences in participant ability, $6 \%$ to variable station difficulty, $25 \%$ to differences in assessor stringency/leniency and $43 \%$ to participant-station interaction (the tendency of students to perform inconsistently across the stations, scoring well on some and poorly on others). The overall G coefficient, a measure of reliability that is considered more appropriate than the better-known Cronbach's alpha, was equal to 0.52 , indicating that $52 \%$ of the variation in overall MMI scores was due to genuine differences in candidate ability. This is again well short of the desirable value of 0.70 .

\section{Relationship between the MMI and original interview scores}

The distribution of the participants' original interview scores (Figure 3) was approximately normal but suffered from a slight ceiling effect that was not present in the MMI scores. The correlation (Pearson's r) between the MMI and original interview scores was 0.15 , a weak value that is not significantly different from zero $(\mathrm{P}=0.110)$. Participants' personal statement scores were uncorrelated with either the original interview scores $(r=-0.03, P=0.772)$ or the MMI scores ( $\mathrm{r}=-0.01, \mathrm{P}=0.895)$. 
Variation by demographic factors

We conducted an analysis of variance (ANOVA) with MMI score as the outcome variable and the participants' age, gender, disability status and cohort group as explanatory variables. There was no significant variation in MMI scores by gender, disability status or cohort group but age was a significant predictor of the MMI score $\left(\mathrm{F}_{1,104}=7.23, \mathrm{P}=0.008\right)$ though the effect was small. Older participants tended to achieve higher scores but a 10 -year increase in age corresponded to only a 5-point increase in MMI score which is well under half the standard deviation of 13.0. Further investigation of this age effect at the station level revealed that age was significantly positively correlated with scores in Station 1 and Station 3 ( $r=0.37$ and 0.45 respectively, $\mathrm{p}<0.001$ in both cases) but not with scores in any of the other stations. A parallel analysis was conducted with the original interview score as the outcome variable and showed no statistically significant variation by any of the four demographic factors.

\section{Role player scores}

Global scores awarded by the role-players in stations 1,2 and 3 were significantly positively correlated with the participants' station scores awarded by the assessors $(r=0.67,0.64$ and 0.78 respectively, $\mathrm{p}<0.001$ in all cases). This suggests that the role-players' scores might validly be incorporated into the overall MMI score.

Predictive validity of the MMI and original selection scores

Using overall scores from each of the four modules undertaken during the first year of the course we examined the extent to which participants' MMI and original selection scores predicted in-course performance. Neither the MMI scores nor the original interview scores were correlated with the module results (Table 4). Even more surprisingly, scores for the 
personal statement, generally regarded as an unreliable measure on which to select applicants, were significantly positively correlated with results for three of the four modules.

\section{DISCUSSION}

This study demonstrates the feasibility of developing and evaluating a values-based MMI for selection to an undergraduate nursing programme using a volunteer sample of current students. By describing the development of the tasks required in the MMI stations and blueprinting these against the values promoted by the NMC and the NHS, the study provides content-related validity evidence for the assessment. Evidence for the response process, in terms of the scoring system, assessor training and prior instructions to the student participants has also been presented.

Analysis of score data from the MMI revealed a distribution that was approximately normal and sufficiently well spread to discriminate between individuals. There was an adequate level of interrater agreement and a degree of internal consistency between six of the seven stations. The reliability of the overall MMI score fell short of the level that would be regarded as desirable for such a high-stakes assessment, with values for Cronbach's alpha and the G coefficient falling outside the ranges found in a systematic review of MMI studies (Pau et al, 2013). Reliability however decreases with the homogeneity of the sample (Streiner \& Norman, 2008, p196) and the use of already-recruited students in the pilot study will have resulted in lower values than would be observed in a sample of actual applicants possessing a wider range of abilities.. A quarter of the station score variance was due to assessor stringency/leniency and this gives scope for improving reliability through training: Griffin and Wilson (2010) found that skills-based training for their MMI assessors reduced the proportion of assessor-related variance from $20.2 \%$ to $7.0 \%$. The large proportion of variance 
in station scores that was due to the tendency of students to perform inconsistently across the stations underlines the well-known phenomenon of context specificity in performance-based assessments (Eva, 2003) and confirms the value of the multiple sampling approach of the MMI in overcoming the danger of basing selection decisions on the outcome of a single interview (Eva, 2004; Roberts, 2008; Patterson et al 2016).

Exploration of the relationship of the MMI scores to other variables found no correlation with either the participants' original selection scores (personal statement and interview scores) or their in-course performance on four first year modules. Although Rankin (2013) in his study on values based practice reported that entrance qualifications to nursing do not predict progression, there is limited research on the predictive ability of the MMI and progression in nursing. Research studies reported in medical education demonstrate a mixed response with some studies reporting a predictive correlation and others showing no correlation (Patterson et al 2016). A surprising finding of our analysis was that scores for the personal statement, generally regarded as an unreliable measure on which to select applicants, were significantly positively correlated with results for three of the four in-course modules.

While being approximately normal, the distribution of participants' original interview scores suffered from a slight ceiling effect suggesting that the current interview method fails to stretch abler candidates. This ceiling effect was not present in the MMI scores.

MMI scores were unrelated to participants' gender or disability status but there was a small effect of age, with older participants tending to achieve slightly higher scores. This relationship was not present for the participants' original interview scores which were unrelated to age, gender or ethnicity. These results suggest that the MMI may slightly advantage older candidates whereas the current interview process does not. Whether this 
indicates that older candidates tend to possess more of the values desirable for a career in nursing is unclear. This correlation between age and higher scores was also reported in Rankin's 2013 study of nurse applicants and individual performance on a nursing programme. Rankin reported that age was a significant predictor of progression with mature candidates more likely to progress.

There is a lack of previous research on examining the reliability and validity of the MMI in a nursing population. A systematic review conducted by Pau et al 2013 for student selection in the healthcare professions did not identify any articles which had evaluated the MMI in nursing despite 30 studies which fulfilled the selection criteria for the study; 26 out of the 30 studies involved medical undergraduates or residents. Perkins et al (2013) have since evaluated the face and content validity of the MMI for selection to undergraduate nursing programmes in London and found acceptable feedback from both participants $(n=890)$ and interviewers $(\mathrm{n}=82)$ involved in the process. However an estimate of the reliability of the selection process was not reported in this study. Our study has examined reliability of the MMI using values in the selection blueprint as well as elements of predictive validity. Patterson et al (2016) in a review of the evidence on values in healthcare, report that there is also very little research on the effectiveness of value congruence and how this relates to care and compassion towards patients.

It is hoped that the results reported in this paper will encourage further empirical studies to evaluate the MMI as a selection methodology in nursing and stimulate further work in this area. Understanding the influence of values on recruitment to nursing is critical to successfully employing the best people to develop a workforce capable of delivering safe and effective patient care. 


\section{Limitations}

The recruitment strategy failed to achieve the target sample size for the MMI pilot though sufficient data were collected to provide a robust analysis.

Comparisons between the MMI and the current interview method in respect of interrater agreement and reliability statistics could not be made as only a single score for each applicant is recorded for the current method so corresponding statistics could not be calculated.

Furthermore this study cannot be generalised to other HEIs, as it examined one group of students in one institution and other institutions are likely to use different selection processes.

\section{CONCLUSION}

More will be expected from the graduate nurse of the future and it is therefore imperative that we get the right people with the right attributes into nursing. This study set out to provide validity evidence for the MMI as a potential tool for the selection of nursing students on to a BSc (Hons) nursing programme. We have shown that implementing an MMI based on the assessment of values is a feasible approach to selection in undergraduate nursing.

\section{Author Contributions:}

All authors have agreed on the final version and meet at least one of the following criteria (recommended by the ICMJE*):

1) substantial contributions to conception and design, acquisition of data, or analysis and interpretation of data;

2) drafting the article or revising it critically for important intellectual content.

* http://www.icmje.org/recommendations/ 


\section{REFERENCES}

Callwood A., Allan H. \& Courtenay M. (2012) Editorial: Are current strategies for preregistration student nurse and student midwife selection 'fit for purpose' from a UK perspective? Introducing the multiple mini interview. Nurse Education Today 32(8), 835-837.

Callwood A., Cooke D. \& Allan H. (2014) Developing and piloting the multiple miniinterview in pre-registration student midwife selection in a UK setting. Nurse Education Today 34(12), 1450-1454.

Cazzell M. \& Rodriguez A. (2011) Qualitative Analysis of Student Beliefs and Attitudes after an Objective Structured Clinical Evaluation: Implications for Affective Domain Learning in Undergraduate Nursing Education. The Journal of Nursing Education 50(12), 711-714.

Cleland J., Dowell J., McLachlan J., Nicholson S. \& Patterson F. (2012) Identifying best practice in the selection of medical students (literature review and interview survey). 106 pages. URL: http://www.gmcuk.org/Identifying_best_practice_in_the_selection_of_medical_students.pdf_51119804.pdf Accessed 19 May 2016.

Draper J. \& Kenward L. (2013) Recruiting the right people into nursing. Available at: http://www.open.edu/openlearn/body-mind/health/nursing/recruiting-the-right-peoplenursing. Accessed on 19 May 2016. 
Eva KW. (2003) On the generality of specificity. Medical Education 37(7), 587-8.

Eva K.W., Rosenfeld J., Reiter H.I., Norman G.R. (2004) An admissions OSCE: the multiple mini-interview. Medical Education 38(3), 314-326.

Fagermoen M.S. (1997) Professional identity: values embedded in meaningful nursing practice. Journal of Advanced Nursing 25(3), 434-441.

Faul F., Erdfelder E., Buchner A. \& Lang A.G. (2009) Statistical power analyses using $\mathrm{G}^{*}$ Power 3.1: tests for correlation and regression analyses. Behavior Research Methods 41(4), 1149-1160.

Francis R. QC (2013) Report of the Mid Staffordshire NHS Foundation Trust Public Inquiry, Chaired by Robert Francis QC.

Griffin B. \& Wilson I.G. (2010) Interviewer bias in medical student selection. Medical Journal of Australia 193(6): 343-346.

Medical Schools Council (MSC) 2013 Selecting for Excellence. End of Year Report. http://www.medschools.ac.uk/Publications/Documents/MSC-Selecting-for-Excellence-Endof-year-report.pdf - Accessed on 19 May 2016.

Morris J.G. (1999) The value and role of the interview in the student admission process: a review. Medical Teacher 21(5) 473-481. 
NHS. Health Education England (2014) Evaluation of values based recruitment in the NHS. February 2014. VBR programme. Literature Review and Evaluation Criteria. Executive Summary. Work Psychology Group. URL:

https://www.hee.nhs.uk/sites/default/files/documents/VBR\%20literature\%20review\%20exec utive\%20summary.pdf. Accessed on 19 May 2016.

NIPEC (Northern Ireland Practice and Education Council for Nursing and Midwifery) (2014) Gateway to Nursing: Report of Phase 2: Attributes which are valued to support career in nursing. September 2014. This document can be downloaded from the NIPEC website www.nipec.hscni.net.

Nursing and Midwifery Council (NMC) (2010) Standards for pre-registration nursing education. 152 pages. http://www.nmc.org.uk/globalassets/sitedocuments/standards/nmcstandards-for-pre-registration-nursing-education.pdf - Accessed on 19 May 2016.

Nursing and Midwifery Council (NMC) (2008) Standards to support learning and assessment in practice. NMC standards for mentors, practice teachers and teachers. 85 pages. https://www.nmc.org.uk/globalassets/sitedocuments/standards/nmc-standards-tosupport-learning-assessment.pdf - Accessed on 23 May 2016.

O’Brien A., Harvey J., Shannon M., Lewis K. \& Valencia O. (2011) A comparison of multiple mini-interviews and structured interviews in a UK setting. Medical Teacher 33(5), 397-402. 
Pau A., Jeevaratnam K., Chen Y.S., Fall A.A., Khoo C. \& Nadarajah V.D. (2013) The Multiple Mini-Interview (MMI) for student selection in health professions training - A systematic review. Medical Teacher 35(12), 1027-41.

Patterson F., Ferguson E., Norfolk T. \& Lane P. (2005) A new selection system to recruit general practice registrars: preliminary findings from a validation study. $B M J$ 330, 711-714.

Patterson F., Prescott-Clements L., Zibarras L., Edwards H., Kerrin M. \& Cousans F. (2016) Recruiting for values in healthcare: a preliminary review of the evidence. Adv in Health Sci Educ 21:859-881

Perkins A., Burton L., Dray B. \& Elcock K. (2013) Evaluation of a multiple-mini-interview protocol used as a selection tool for entry to an undergraduate nursing programme. Nurse Education Today 33(5), 465-469.

Pitt V., Powis D., Levett-Jones T. \& Hunter S. (2014) Nursing students' personal qualities: A descriptive study. Nurse Education Today 34(9), 1196-1200.

Poole P., Moriarty H., Wearn A, Wilkinson T. \& Weller J (2009) Medical Student Selection in New Zealand: Looking to the future. The New Zealand Medical Student Journal. 122(1306); 88-100.

Randall R., Stewart P., Farrell K. \& Patterson F. (2006) Using an assessment centre to select doctors for postgraduate training in obstetrics and gynaecology. The Obstetrician \& Gynaecologist. 8(4), 257-262. 
Rankin B. (2013) Emotional intelligence: enhancing values-based practice and compassionate care in nursing. Journal of Advanced Nursing 69(12), 2717-2725. Doi: 10.1111/jan.12161

Roberts C., Walton M., Rothnie I., Crossley J., Lyon P., Kumar K. \& Tiller D. (2008) Factors affecting the utility of the multiple mini-interview in selecting candidates for graduate-entry medical school. Medical Education 42(4), 396-404.

Taylor R., Macduff C. \& Stephen A. (2014) A national study of selection processes for student nurses and midwives. Nurse Education Today 34(8), 1155-1160.

Traynor M., \& Galanouli D. (2015) Have OSCEs come of age in nursing education? British Journal of Nursing 24(7), 388-391.

Weis D. \& Schank M.J. (2000) An instrument to measure professional nursing values. Journal of Nursing Scholarship 32(2), 201-204.

This article is protected by copyright. All rights reserved. 
Table 1: Descriptive statistics for station scores

\begin{tabular}{cccccc}
\hline Station & Name & Minimum & Maximum & Mean & SD \\
\hline 1 & Disclose information & 8 & 23 & 15.8 & 2.9 \\
2 & Neighbour's dog & 4 & 23 & 14.9 & 4.1 \\
3 & Distressed classmate & 4 & 24 & 16.6 & 3.8 \\
4 & Social media & 9 & 24 & 18.0 & 4.5 \\
5 & Essay & 4 & 24 & 16.1 & 3.4 \\
6 & Personal statement & 6 & 24 & 15.8 & 3.3 \\
7 & Committee & 8 & 24 & 17.1 & 4.0 \\
\hline
\end{tabular}

Table 2 Pearson correlation coefficients ( $P$ value) between station scores and corrected MMI score

\begin{tabular}{|c|c|c|c|c|c|c|c|}
\hline & $\begin{array}{l}\text { Station } \\
1\end{array}$ & $\begin{array}{l}\text { Station } \\
2\end{array}$ & $\begin{array}{l}\text { Station } \\
3\end{array}$ & $\begin{array}{l}\text { Station } \\
4\end{array}$ & $\begin{array}{l}\text { Station } \\
5\end{array}$ & $\begin{array}{l}\text { Station } \\
6\end{array}$ & $\begin{array}{l}\text { Station } \\
7\end{array}$ \\
\hline & 0.35 & & & & & & \\
\hline Station 2 & $(<0.001)$ & & & & & & \\
\hline & 0.40 & 0.05 & & & & & \\
\hline Station 3 & $(<0.001)$ & (0.570) & & & & & \\
\hline & 0.08 & -0.24 & 0.22 & & & & \\
\hline Station 4 & (0.385) & $(0.013)$ & (0.018) & & & & \\
\hline & 0.11 & 0.20 & 0.06 & -0.04 & & & \\
\hline Station 5 & $(0.245)$ & (0.034) & (0.531) & (0.655) & & & \\
\hline & 0.03 & 0.29 & 0.06 & -0.06 & 0.16 & & \\
\hline Station 6 & (0.765) & (0.002) & (0.520) & (0.515) & $(0.090)$ & & \\
\hline & 0.12 & 0.30 & 0.19 & 0.05 & 0.23 & 0.22 & \\
\hline Station 7 & (0.224) & $(0.001)$ & $(0.052)$ & $(0.615)$ & $(0.014)$ & $(0.021)$ & \\
\hline $\begin{array}{l}\text { Corrected } \\
\text { MMI score* }\end{array}$ & $\begin{array}{r}0.36 \\
(<0.001)\end{array}$ & $\begin{array}{r}0.27 \\
(0.005)\end{array}$ & $\begin{array}{r}0.31 \\
(0.001)\end{array}$ & $\begin{array}{r}0.00 \\
(0.967)\end{array}$ & $\begin{array}{r}0.22 \\
(0.019)\end{array}$ & $\begin{array}{r}0.23 \\
(0.018)\end{array}$ & $\begin{array}{r}0.36 \\
(<0.001)\end{array}$ \\
\hline
\end{tabular}

${ }^{*}$ MMI score excluding that station

This article is protected by copyright. All rights reserved. 
Table 3: Interrater agreement (intraclass correlation coefficients) in stations 1, 2, 3 and 6.

\begin{tabular}{cccccccc}
\hline Station & $\begin{array}{c}\mathrm{N} \\
\text { students }\end{array}$ & $\begin{array}{c}\text { N assessor } \\
\text { pairs }\end{array}$ & $\begin{array}{c}\text { Value 1 } \\
\text { rating }\end{array}$ & $\begin{array}{c}\text { Value 2 } \\
\text { rating }\end{array}$ & $\begin{array}{c}\text { Value 3 } \\
\text { rating }\end{array}$ & $\begin{array}{c}\text { Global } \\
\text { rating }\end{array}$ & $\begin{array}{c}\text { Station } \\
\text { total }\end{array}$ \\
\hline 1 & 27 & 1 & 0.53 & 0.54 & 0.43 & 0.57 & 0.62 \\
2 & 25 & 2 & 0.85 & 0.85 & 0.87 & 0.87 & 0.90 \\
3 & 27 & 1 & 0.70 & 0.80 & 0.89 & 0.88 & 0.89 \\
6 & 27 & 2 & 0.46 & 0.43 & 0.60 & 0.49 & 0.62 \\
\hline
\end{tabular}

Table 4 Pearson correlation coefficients ( $P$ value) between MMI scores, original selection scores and first year module scores

\begin{tabular}{lrrrr}
\hline & $\begin{array}{r}\text { Module A } \\
\text { Health\& } \\
\text { Wellbeing } \\
(\mathrm{N}=96)\end{array}$ & $\begin{array}{r}\text { Module B } \\
\text { Evidence } \\
\text { Based } \\
\text { Nursing } \\
(\mathrm{N}=93)\end{array}$ & $\begin{array}{r}\text { Module C } \\
\text { Professional } \\
\text { Nursing } \\
\text { Values } \\
(\mathrm{N}=95)\end{array}$ & $\begin{array}{r}\text { Module D } \\
\text { Practice } \\
\text { Module 1 } \\
(\mathrm{N}=94)\end{array}$ \\
\hline MMI score & 0.07 & 0.03 & 0.06 & 0.03 \\
Original interview Score & $(0.492)$ & $(0.757)$ & $(0.588)$ & $(0.753)$ \\
& -0.02 & 0.11 & 0.04 & -0.06 \\
Personal Statement Score & $(0.824)$ & $(0.296)$ & $(0.705)$ & $(0.558)$ \\
& $\mathbf{0 . 2 2}$ & $\mathbf{0 . 3 1}$ & $\mathbf{0 . 2 4}$ & 0.14 \\
& $\mathbf{( 0 . 0 2 9 )}$ & $\mathbf{( 0 . 0 0 2 )}$ & $\mathbf{( 0 . 0 1 9 )}$ & $(0.175)$ \\
\hline
\end{tabular}

This article is protected by copyright. All rights reserved. 
Figure 1: Values and stations

\begin{tabular}{|c|c|c|c|c|c|c|}
\hline & \multicolumn{6}{|c|}{ Values } \\
\hline Station & Trust & Integrity & Accountability & $\begin{array}{c}\text { Personal } \\
\text { development }\end{array}$ & $\begin{array}{c}\text { Person } \\
\text { Centeredness }\end{array}$ & $\begin{array}{l}\text { Team } \\
\text { working }\end{array}$ \\
\hline $\begin{array}{l}\text { A patient } \\
\text { discloses } \\
\text { some } \\
\text { information }\end{array}$ & $x$ & & $x$ & & $x$ & \\
\hline $\begin{array}{l}\text { The } \\
\text { Neighbour's } \\
\text { Dog }\end{array}$ & $x$ & & $x$ & & $x$ & \\
\hline $\begin{array}{l}\text { Distressed } \\
\text { Classmate }\end{array}$ & $X$ & & $x$ & & $x$ & \\
\hline $\begin{array}{l}\text { Social } \\
\text { Media }\end{array}$ & & $x$ & $x$ & & $x$ & \\
\hline The Essay & $x$ & & $x$ & $x$ & & \\
\hline $\begin{array}{l}\text { Candidate's } \\
\text { Personal } \\
\text { Statement }\end{array}$ & & & & $x$ & $x$ & $x$ \\
\hline $\begin{array}{l}\text { The } \\
\text { Committee }\end{array}$ & & & & $x$ & $x$ & $x$ \\
\hline
\end{tabular}

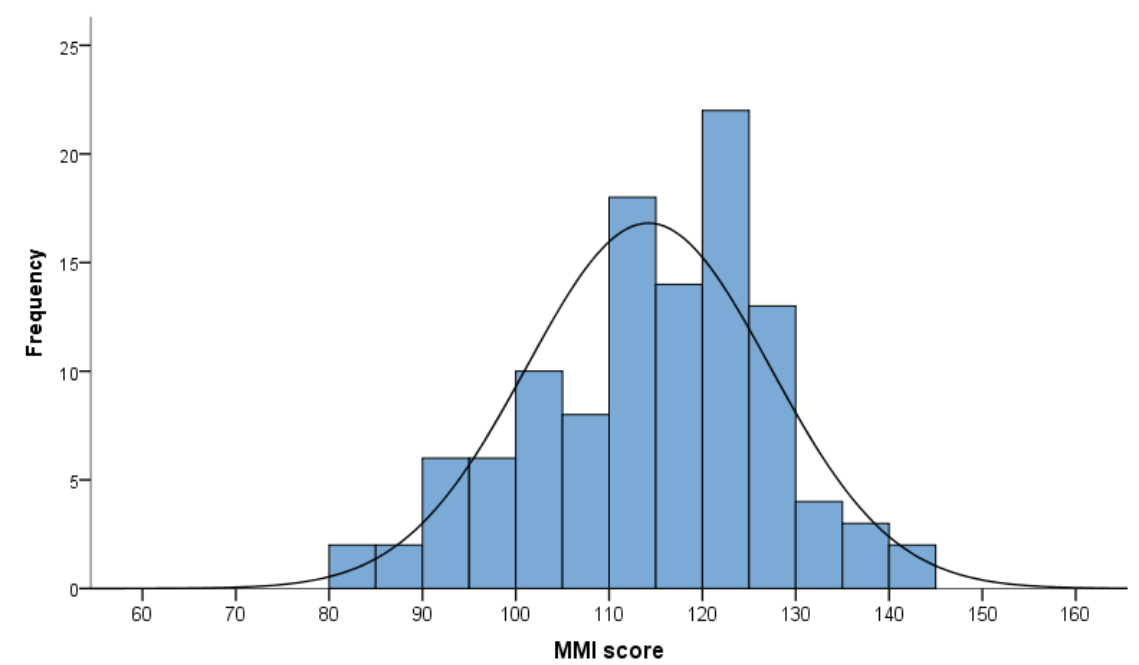

Figure 2: Histogram of total MMI scores with normal distribution curve

This article is protected by copyright. All rights reserved. 


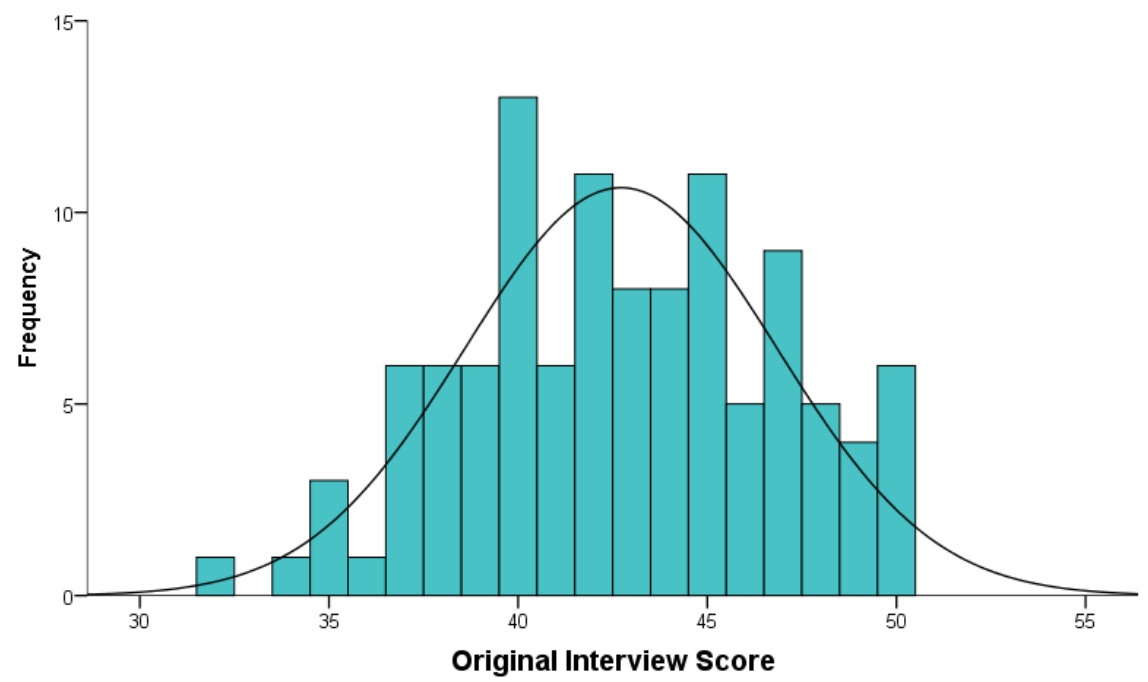

Figure 3: Histogram of original interview scores with normal distribution curve

This article is protected by copyright. All rights reserved. 